Check for updates

Cite this: RSC Adv., 2019, 9, 22636

\title{
Reduction of Escherichia coli 0157:H7 and naturally present microbes on fresh-cut lettuce using lactic acid and aqueous ozone
}

\author{
Jiayi Wang, (D) a Shan Wang, ${ }^{a}$ Yeting Sun, ${ }^{\text {ab }}$ Chen Li, ${ }^{a}$ Yanru Li, ${ }^{a}$ Qi Zhang ${ }^{a}$ \\ and Zhaoxia Wu*a
}

Lactic acid (LA) is an effective sanitizer for disinfection of fresh produce. Tap water is generally used to wash disinfected fresh produce because sanitizer residues negatively affect the quality and organoleptic properties of the produce. However, tap water is ineffective for secondary disinfection compared with sanitizers. Thus, we propose a disinfection method using LA plus aqueous ozone (AO), an oxidizing sanitizer that does not lead to secondary residue. We compared the proposed method of 1\% LA (90 s) plus $1 \mathrm{mg} \mathrm{L}^{-1} \mathrm{AO}(30 \mathrm{~s})$ or $2 \mathrm{mg} \mathrm{L}^{-1} \mathrm{AO}(30 \mathrm{~s})$ with the traditional method of $100 \mathrm{ppm}$ chlorine (120 s) or $1 \%$ LA (120 s) plus tap water (30 s) and $2 \mathrm{mg} \mathrm{L}^{-1} \mathrm{AO}$ (150 s). Microbial analysis showed that LA plus AO led to the greatest reductions in microbes (Escherichia coli O157:H7, aerobic mesophilic counts, aerobic psychrophilic counts, moulds, and yeasts) during storage (0-5 days at $5{ }^{\circ} \mathrm{C}$ ). Quality analysis (colour, sensory qualities, electrolyte leakage, polyphenolic content, and weight loss) showed that LA + AO did not cause additional quality loss compared with tap water treatment. These results indicate that the hurdle technology proposed (LA plus $A O$ ) has a good potential for use in fresh produce disinfection.

Received 12th May 2019

Accepted 18th July 2019

DOI: $10.1039 / c 9 r a 03544 c$

rsc.li/rsc-advances produce. $^{7}$ However, the low-cost and easy-to-use characteristics of chemical sanitizers have not been challenged. ${ }^{8-10}$ Chemical sanitizers are generally divided into two categories, i.e., oxidizing agents and organic acids. As typical oxidizing agents, chlorine-based sanitizers have been widely used for fresh produce disinfection at free chlorine concentrations ranging from 50 to $200 \mathrm{ppm}$ and for a maximum disinfection time of 5 min. ${ }^{11}$ However, during the washing process, chlorine in disinfectants can react with organic matter to form carcinogenic and mutagenic compounds, such as chloroform, trihalomethanes, chloramines, and haloacetic acids. ${ }^{9,12,13}$ The EU has therefore significantly restricted the use of chlorine for fresh produce disinfection, and in several EU countries, including Germany, the Netherlands, Switzerland, and Belgium, disinfection of fresh produce using chlorine is prohibited. ${ }^{12}$ Most organic acids are approved as generally recognized as safe (GRAS) by the US Food and Drug Administration and are used as a pH regulators and flavouring agents in the food industry. Organic acids are superior to chlorine because they do not generate toxic or carcinogenic compounds. ${ }^{9}$ When comparing disinfection efficacy, organic acids are more effective than chlorine-based sanitizers. For example, lactic acid (LA) is more effective than sodium hypochlorite $(\mathrm{SH})$ in reducing Listeria innocua on broccoli sprouts. ${ }^{14}$ LA causes a more significant reduction in E. coli and Salmonella counts on spinach than gaseous chlorine dioxide; ${ }^{15}$ the commercially available sanitizer Purac (containing 90\% LA, adjusted to $2 \%$ for use) is superior to chlorine for controlling the growth of mould and yeast during 
storage. ${ }^{16}$ Citric acid (CA) is better than $\mathrm{SH}$ to control E. coli and L. innocua on spinach during storage. ${ }^{17} \mathrm{LA}, \mathrm{CA}$, and acetic acid (AA) are commonly used for minimal processing. ${ }^{10}$ Other GRAS organic acids (i.e., succinic acid [SA], tartaric acid [TA], propionic acid [PA], and malic acid [MA]) are also used to disinfect fresh produce. ${ }^{9,18,19}$ Among these seven GRAS acids, we previously showed that LA reduced the aerobic mesophilic count (AMC) the most on lettuce. ${ }^{20}$ Huang and Chen ${ }^{18}$ compared the disinfection effects between LA, CA, MA, TA, and AA and found that LA caused the greatest reduction in E. coli $\mathrm{O} 157: \mathrm{H} 7$ on spinach. Moreover, Akbas and Olmez found that the reduction in $L$. monocytogenes caused by LA was significantly higher than those by AA and CA. ${ }^{21}$

Although organic acids have many advantages, acid residues often remain on produce after use, giving the produce poor organoleptic characteristics and affecting the visual quality of the produce. ${ }^{\mathbf{1 0 , 2 2}}$ Thus, tap water is generally used to wash fresh produce after acid disinfection. However, this method is ineffective for secondary disinfection and could lead to crosscontamination of the disinfected produce under circulation. ${ }^{23-25}$ Thus, there is a need for a sanitizer with additional microbial reduction capacity to be used following acid disinfection for removal of acid residues without leaving secondary residues.

Ozone has been deemed as GRAS and is widely used as a sanitizer owing to its low cost (produced from air), efficacy, and lack of residue deposition (because it is unstable and will decompose to oxygen). Aqueous ozone (AO, 1-3 ppm) shows microbial reduction capacity comparable to that of $100 \mathrm{ppm}$ chlorine on lettuce. ${ }^{\mathbf{1 0}}$ Moreover, disinfection efficacy is enhanced by the combined use of $\mathrm{AO}$ and organic acids. For example, the combination of $3 \mathrm{ppm} \mathrm{AO}$ and $1 \% \mathrm{CA}$ reduces $E$. coli counts on lettuce to a greater extent than either one did alone. ${ }^{26}$ A similar effect was observed with $E$. coli and L. monocytogenes on mushrooms treated with both 3 ppm AO and 1\% $\mathrm{CA}^{27}$ On durum wheat, AO plus AA is more effective against native microbiota than $\mathrm{AO}, \mathrm{AA}$, or chlorinated water alone. ${ }^{28}$ Additionally, AO plus MA not only caused the greatest reduction in Shigella spp. counts but also stimulated radical scavenging activity in radishes and mung bean sprouts. ${ }^{29}$ Moreover, the low-pH environment caused by organic acid can shorten AO preparation time and prolong the half-life of $\mathrm{AO} .{ }^{28}$ However, the combined use of $\mathrm{AO}$ and organic acids can leave acid residues on fresh produce.

Accordingly, in this study, we used AO instead of tap water to wash fresh-cut lettuce disinfected with LA and evaluated the effects of this sequential washing method on the quality of lettuce and on its microbial counts (naturally present and inoculated E. coli $\mathrm{O} 157: \mathrm{H7})$.

\section{Materials and methods}

\section{Sample preparation}

Green leaf lettuce (Lactuca sativa var. Crispa L.) was purchased from a local market on the day of the experiment. Two outer leaves, inner baby leaves, broken leaves, and stems were removed. The remaining parts were rinsed with tap water to remove the soil. A circle knife was used to cut the lettuce into pieces with a diameter of approximately $5.8 \mathrm{~cm} .{ }^{20}$ Excess water was removed using a manual salad spinner.

\section{Inoculation of lettuce leaves}

Nontoxic E. coli O157:H7 (ATCC700728) was kindly provided by Dr Yeting Sun, Vegetable Research Center, Beijing Academy of Agriculture and Forestry Sciences. Obtained cultures were stored in $50 \%$ glycerol solution at a ratio of $1: 1 .^{30}$ Before every use, the stock culture was purified using sorbitol MacConkey agar (SMAC; Hopebio, Qingdao, China). Then, single colonies were inoculated into tryptic soy broth medium (Hopebio) to prepare the working culture. The inoculation was carried out as previously reported by Huang and Chen, ${ }^{\mathbf{1 8}}$ with slight modifications. Briefly, the working culture was adjusted to approximately $10^{9} \mathrm{CFU} \mathrm{mL}^{-1}$ (optical density at $600 \mathrm{~nm}$ ). Then, $5 \mathrm{~mL}$ of the adjusted cell suspension was mixed with $200 \mathrm{~mL} 0.85 \%$ sodium chloride in a sterilized plastic bag, and $10 \mathrm{~g}$ of the lettuce leaves was submerged in the cell suspension and gently massaged for $5 \mathrm{~min}$. The drained leaves $\left(10^{6}\right.$ to $\left.10^{7} \mathrm{CFU} \mathrm{g}^{-1}\right)$ were placed in a sterilized plastic box for $24 \mathrm{~h}$ at $4{ }^{\circ} \mathrm{C}$ to facilitate the attachment of bacteria.

\section{AO preparation}

Ozone was prepared using the corona discharge method. Oxygen and ozone generators were mounted on a machine $(20 \mathrm{~g}$ $\mathrm{h}^{-1}$; Ruifeng Technology, Zhuhai, China), and dried oxygen was introduced into the corona discharge pipe to obtain highly pure gaseous ozone. Tap water was used to prepare AO; $30 \mathrm{~L}$ water was introduced into the tank and circulated using a gas-liquid mixing pump (1000 kg h ${ }^{-1}$; CNP, Hangzhou, China). Gaseous ozone was absorbed by the pump and circulated. The AO concentration gradually increased and was measured in realtime using an ozone electrochemical probe $\left(0-20 \mathrm{mg} \mathrm{L}^{-1}\right.$; Nobo Science, Qingdao, China); data were corrected using the indigo method. ${ }^{31}$ The principle of electrochemical detection of ozone concentration was the same, regardless of the manufacturer chosen. The correction process was as follows.

(1) To prepare indigo stock solution, $50 \mathrm{~mL}$ distilled water, $0.1 \mathrm{~mL}$ concentrated hydrochloric acid (analytical grade), and $77 \mathrm{mg}$ potassium indigotrisulfonate (Sigma-Aldrich, St. Louis, MO, USA) were thoroughly mixed and the final volume was adjusted to $100 \mathrm{~mL}$ in a volumetric flask. The solution was allowed to stand for 4 months in the dark.

(2) To prepare indigo working solution, $50 \mathrm{~mL}$ of distilled water, $10 \mathrm{~mL}$ indigo stock solution, $1 \mathrm{~g}$ sodium dihydrogen phosphate (analytical grade), and $0.7 \mathrm{~mL}$ concentrated phosphoric acid (analytical grade) were thoroughly mixed and the final volume was adjusted to $100 \mathrm{~mL}$ in a volumetric flask. The solution was used within one week.

(3) The electrode was placed in tap water and the concentration was adjusted to zero.

(4) When the electrode was thoroughly oxidized by the AO (at least $5 \mathrm{~min}$ ), electrical signals on the screen were recorded and $5 \mathrm{~mL}$ of AO flowing through the electrode were transferred to volumetric flask B $(100 \mathrm{~mL}$; containing $10 \mathrm{~mL}$ indigo working solution, $1 \mathrm{~mL}$ of $5 \%$ malonic acid, and $50 \mathrm{~mL}$ of distilled 
water). The final volume was adjusted to $100 \mathrm{~mL}$. Tap water in flask A was used as a blank. The absorbance at $600 \mathrm{~nm}$ was measured. The concentration of dissolved ozone was calculated using the following formula:

Dissolved ozone concentration $\left(\mathrm{mg} \mathrm{L}^{-1}\right)=(\Delta A \times 100) /(f \times b \times v)$

where $\Delta A$ is the absorbance difference between flasks $\mathrm{A}$ and $\mathrm{B}, f$ is $0.42, b$ is the cuvette width (usually $1 \mathrm{~cm}$ ), and $v$ is the added sample volume ( $5 \mathrm{~mL}$ in this experiment).

(5) The AO was re-prepared and the concentration was adjusted to the calculated value when the same electrical signal was recorded.

\section{Sequential washes}

Lettuce samples and AO were prepared as described above. LA (90\% purity; Macklin, Shanghai, China) was prepared as a $1 \%$ solution. Chlorinated water was prepared using $\mathrm{SH}$ (Sinopharm, Beijing, China) and adjusted to the desired concentration using a free chlorine test kit (Lohand, Hangzhou, China; 0.05$\left.1 \mathrm{mg} \mathrm{L}^{-1}\right)$. To select the appropriate contact time for LA plus AO, a screening experiment was designed (Table 1). We examined whether LA plus AO could shorten the disinfection time while having similar or better disinfection effects. Thus, the processing time of LA plus tap water was set at $120 \mathrm{~s}$ plus $30 \mathrm{~s}$. Based on the screening results, the selected experimental groups, disinfection times, and sanitizer concentrations are shown in Table 2. Lettuce samples (for naturally presented

Table 1 Effects of contact times and concentrations of $L A$ and $A O$ on E. coli O157: $\mathrm{H} 7$ reduction $^{a}$

\begin{tabular}{|c|c|c|}
\hline \multicolumn{2}{|l|}{ Treatment } & \multirow{2}{*}{$\begin{array}{l}\text { E. coli } \mathrm{O} 157: \mathrm{H} 7 \\
\text { reduction }\left(\log \mathrm{CFU} \mathrm{g}^{-1}\right)\end{array}$} \\
\hline First stage & Second stage & \\
\hline Tap water $120 \mathrm{~s}$ & & $0.38 \pm 0.15 a$ \\
\hline $1 \%$ LA $120 \mathrm{~s}$ & Tap water $30 \mathrm{~s}$ & $1.41 \pm 0.18 c$ \\
\hline $1 \%$ LA $60 \mathrm{~s}$ & $0.5 \mathrm{mg} \mathrm{L}^{-1} \mathrm{AO} 60 \mathrm{~s}$ & $1.12 \pm 0.16 b$ \\
\hline $1 \%$ LA $60 \mathrm{~s}$ & $1.0 \mathrm{mg} \mathrm{L}^{-1} \mathrm{AO} 60 \mathrm{~s}$ & $1.28 \pm 0.15 b c$ \\
\hline $1 \%$ LA $60 \mathrm{~s}$ & $2.0 \mathrm{mg} \mathrm{L}^{-1} \mathrm{AO} 60 \mathrm{~s}$ & $1.38 \pm 0.03 \mathrm{c}$ \\
\hline $1 \%$ LA $90 \mathrm{~s}$ & $0.5 \mathrm{mg} \mathrm{L}^{-1} \mathrm{AO} 30 \mathrm{~s}$ & $1.45 \pm 0.10 c$ \\
\hline $1 \%$ LA $90 \mathrm{~s}$ & $1.0 \mathrm{mg} \mathrm{L}^{-1} \mathrm{AO} 30 \mathrm{~s}$ & $1.70 \pm 0.08 \mathrm{~d}$ \\
\hline $1 \%$ LA $90 \mathrm{~s}$ & $2.0 \mathrm{mg} \mathrm{L}^{-1} \mathrm{AO} 30 \mathrm{~s}$ & $1.72 \pm 0.16 \mathrm{~d}$ \\
\hline
\end{tabular}

${ }^{a}$ AO, aqueous ozone; LA, lactic acid. Different letters in a column indicate a significant difference $(P<0.05)$. Values are expressed as means \pm standard deviations.

Table 2 Experimental settings ${ }^{a}$

Disinfection stage $\quad$ Sanitizer residue removal stage

Tap water (control) $150 \mathrm{~s}$

$2 \mathrm{mg} \mathrm{L}^{-1} \mathrm{AO} 150 \mathrm{~s}$

$100 \mathrm{mg} \mathrm{L}^{-1}$ free chlorine $120 \mathrm{~s} \quad$ Tap water $30 \mathrm{~s}$

$1 \%$ LA $120 \mathrm{~s}$

$1 \%$ LA $90 \mathrm{~s}$

Tap water $30 \mathrm{~s}$

$1 \mathrm{mg} \mathrm{L}^{-1} \mathrm{AO} 30 \mathrm{~s}$

$1 \%$ LA $90 \mathrm{~s}$

$2 \mathrm{mg} \mathrm{L}^{-1}$ AO $30 \mathrm{~s}$ microbial analysis) and inoculated samples (for E. coli O157:H7 analysis) were dipped in sanitizers at a ratio of $1: 20(\mathrm{w} / \mathrm{v})$ and shaken at $150 \mathrm{rpm}$. After washing, samples were dewatered using an alcohol-sterilized salad spinner. Then, samples were transferred to a polyethylene terephthalate box $(18 \times 13 \times 4$ $\mathrm{cm}$ ), and packaged using a polyvinyl chloride cling film (Nan Ya, Tai Wan, China) under air. ${ }^{\mathbf{1 6}}$ Considering the short shelf-life of minimally processed products and consumer demand for fresh products, the samples were stored for 5 days at $5{ }^{\circ} \mathrm{C}$. Samples without disinfection were selected as the control group. Each treatment was independently performed three times.

\section{Microbiological analysis}

Microbes were counted at 0,3 , and 5 days. To guarantee complete contact between the lettuce sample and the dilution, after opening the package, each piece was divided into four parts on sterilized gauze and manually mixed. A $5 \mathrm{~g}$ sample was immersed in $70 \mathrm{~mL}$ sterile $0.85 \%$ sodium chloride solution and shaken at $260 \mathrm{rpm}$ for $3 \mathrm{~min}$ to prepare a 15-fold dilution. A 10fold dilution series (minimum dilution series of 100-fold) was prepared in $0.85 \%$ sodium chloride solution as needed. For AMC and aerobic psychrophilic counts (APCs), a $1 \mathrm{~mL}$ dilution was pour-plated in plate count agar (Hopebio) and incubated for 2 days at $37{ }^{\circ} \mathrm{C}$ or 10 days at $7{ }^{\circ} \mathrm{C}$, respectively. For M\&Y, a $1 \mathrm{~mL}$ dilution was pour-plated in Bengal rose agar (Hopebio) and incubated for 5 days at $28{ }^{\circ} \mathrm{C}$. For E. coli $\mathrm{O} 157: \mathrm{H} 7$, a $0.1 \mathrm{~mL}$ dilution was surface-plated on SMAC agar and incubated for 1 day at $37^{\circ} \mathrm{C}$. Three replicates were analysed in duplicate, and the results were expressed as $\log \mathrm{CFU} \mathrm{g}^{-1}$.

\section{Colour and sensory quality analyses}

Colour determination was performed as described by Zhang and Yang, ${ }^{32}$ with some modifications. At the end of the storage period (5 days), $L^{*}, a^{*}$, and $b^{*}$ values were determined using a colorimeter (CR400; Konica Minolta, Osaka, Japan), which was calibrated using a white standard plate $(Y=82.80, x=0.3194, y$ $=0.3264$ ) before use. Ten pieces of lettuce were randomly selected from each group, and two sites per piece were analysed for a total of 20 readings per treatment.

Sensory analysis was performed as described by Allende et al. ${ }^{33}$ with some modifications. Briefly, quality characteristics, including sensory colour, crispness, and odour, were evaluated on day 5. Eight PhD students from the College of Food Science, Shenyang Agricultural University were invited to score using the following scale: 0 , very bad, not characteristic of the product; 5 , acceptability threshold; and 10, very good product characteristics. The samples were placed on trays with marks at the bottom, and the trays were randomly reorganized to minimize subjectivity and to ensure test accuracy. During evaluation, only one person was allowed to enter the room $\left(30 \mathrm{~m}^{2}, 2.8 \mathrm{~m}\right.$ height; illuminated by a $96 \mathrm{~W}$ white light lamp) and was not allowed to communicate with others after evaluation. 


\section{Electrolyte leakage, weight loss, and polyphenolic content evaluations}

The extent of damage to the lettuce after washing was estimated by measuring electrolyte leakage as previously described, ${ }^{34}$ with some modifications. Briefly, $5 \mathrm{~g}$ of washed sample was immersed in $250 \mathrm{~mL}$ distilled water $\left(1-3 \mu \mathrm{sm}^{-1}\right)$ for $20 \mathrm{~s}$ to remove acid residue, which can interfere with conductivity measurements. Then, the samples were immersed in $150 \mathrm{~mL}$ distilled water, and the conductivity was measured after $30 \mathrm{~s}$ and $30 \mathrm{~min}$. After incubation for $24 \mathrm{~h}$ at $-20{ }^{\circ} \mathrm{C}$, the sample was allowed to stand overnight at room temperature, and the conductivity was measured again. Electrolyte leakage was calculated using the following formula:

Electrolyte leakage $(\%)=\left(\right.$ conductivity $_{30 \mathrm{~min}}-$ conductivity $\left._{0.5 \mathrm{~min}}\right) /$ (conductivity ${ }_{24} \mathrm{~h}-$ conductivity $_{0.5 \mathrm{~min}}$ )

Weight loss was analysed on day 5 and calculated using the following formula:

$$
\text { Weight loss }(\%)=1-\left(\text { weight }_{\mathrm{d} 5} / \text { weight }_{\mathrm{d} 0}\right)
$$

Polyphenolic content was analysed on day 5. Briefly, $5 \mathrm{~g}$ fresh sample was extracted using $75 \mathrm{~mL}$ of $80 \%$ methanol in a blender for $2 \mathrm{~min}$. After allowing the mixture to stand for $2 \mathrm{~h}$ at $4{ }^{\circ} \mathrm{C}$, the slurry was filtered and centrifuged at $12000 \times g$ for $10 \mathrm{~min}$. Polyphenolic content was determined according to the Folin-Ciocalteu method, ${ }^{35}$ with some modifications. Briefly, $50 \mu \mathrm{L}$ of the suspension was added to $3 \mathrm{~mL}$ distilled water and oxidized with $250 \mu \mathrm{L}$ Folin reagent. After allowing the mixture to stand for $6 \mathrm{~min}$, the reaction was neutralised by adding $750 \mu \mathrm{L}$ of $20 \%$ sodium carbonate and then incubated for $90 \mathrm{~min}$ in the dark. The absorbance was read at $765 \mathrm{~nm}$, and the results are expressed as gallic acid equivalent (GAE, $\mathrm{mg} \mathrm{kg}^{-1}$ ) expressed on a fresh weight basis.

\section{Acid removal capacity}

The acid removal capacity of AO and tap water was evaluated based on changes in conductivity. Following treatment with $1 \%$ LA for $90 \mathrm{~s}$, samples were transferred to $150 \mathrm{~mL}$ tap water or 1 or $2 \mathrm{mg} \mathrm{L}^{-1}$ AO solutions without dewatering, and conductivity was measured within $150 \mathrm{~s}$.

\section{Statistical analysis}

Differences between group means were evaluated using analysis of variance with the Statistical Package for the Social Sciences (SPSS) v.20 software (SPSS, Chicago, IL, USA), and differences $(P<0.05)$ in mean values were analysed using Duncan's multiple range test.

\section{Results and discussion}

\section{Effects of sequential washing on lettuce colour and sensory quality}

The screening results showed that $E$. coli $\mathrm{O} 157: \mathrm{H} 7$ counts in the control group were $6.57 \pm 0.15 \log \mathrm{CFU} \mathrm{g^{-1 }}$. After disinfection,
$90 \mathrm{~s} \mathrm{LA} \mathrm{plus} 30 \mathrm{~s} 1 \mathrm{mg} \mathrm{L}^{-1} \mathrm{AO}$ and $90 \mathrm{~s} \mathrm{LA} \mathrm{plus} 30 \mathrm{~s} 2 \mathrm{mg} \mathrm{L}^{-1} \mathrm{AO}$ reduced the levels by 1.70 and $1.72 \log \mathrm{CFU} \mathrm{g^{-1 }}$, respectively, which were significantly higher than those of the other combination groups (Table 1). In addition, this was important considering that a short contact time is important for AO disinfection. ${ }^{36}$ Similarly, organic acid disinfection is unfeasible if the contact time exceeds $5 \mathrm{~min}$, even if it yields a significant reduction in microbial counts. ${ }^{10}$ Thus, this dual combination (i.e., $90 \mathrm{~s} \mathrm{LA}$ plus $30 \mathrm{~s} \mathrm{AO}$ ) was selected.

Colour analysis showed that all disinfection treatments had no effect on $L^{*}, a^{*}$, and $b^{*}$ values relative to samples treated with tap water (Fig. 1a-c). There were also no differences in colour between samples washed with LA (90 s) plus $\mathrm{AO}(30 \mathrm{~s})$ and LA $(120 \mathrm{~s})$. However, it has been reported that oxidizing sanitizers affect lettuce colour to a greater extent than organic acid; one group reported that the $L^{*}$ value was increased relative to the control following treatment with $5 \mathrm{ppm}$ ozone for $15 \mathrm{~min}$, whereas $0.5-1.5 \%$ CA did not alter colour quality. ${ }^{37}$ After treatment with $2 \%$ LA and vinegar (6\% acetic acid) followed by storage for 7 days, the $b^{*}$ values of lettuce were 21.0 and 18.2 respectively, which were comparable to that of the untreated sample (18.0); whereas the $b^{*}$ value of samples treated with $300 \mathrm{ppm}$ SH was 37.1. ${ }^{38} \mathrm{~A}$ previous report showed that AO concentrations higher than $5 \mathrm{mg} \mathrm{L}^{-1}$ can cause physiological injury to the produce. ${ }^{10}$ Thus, our inconsistent observations in this study may be related to the low $\mathrm{AO}\left(1\right.$ and $\left.2 \mathrm{mg} \mathrm{L}^{-1}\right)$ and chlorine $(100 \mathrm{ppm})$ concentrations and the short AO contact time (30 s).

Sensory analysis showed that the colour was consistent with the colour observed using the colorimeter, indicating that the various treatments did not negatively affect the colour quality (Fig. 1d). The sensory odour and crispness scores were consistent with those of the control group on day 5 and exceeded the acceptability threshold ( 5 points, Fig. 1e and f), similar to the results described by Martínez-Sánchez et al. ${ }^{16}$
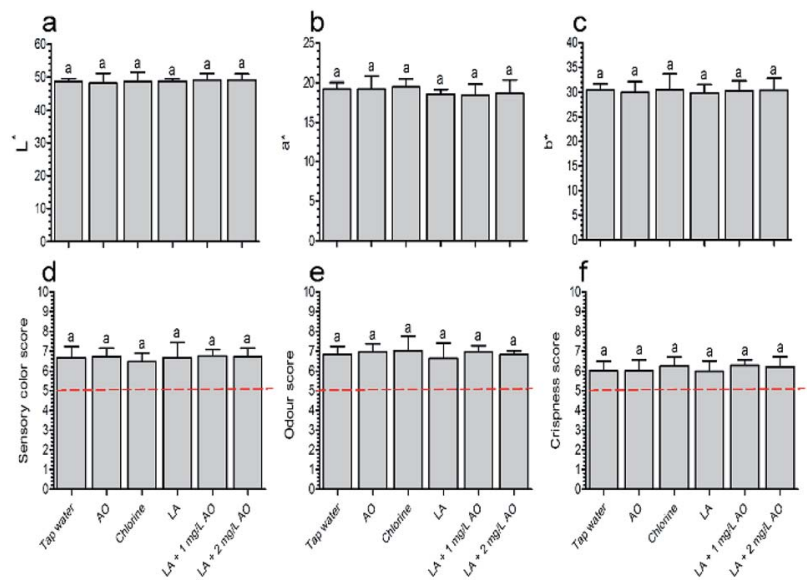

Fig. 1 Effects of various treatments on colour $(a-c)$ and sensory quality $(d-f)$ at the end of storage ( 5 days). The red dotted line indicates the acceptability threshold value (i.e., 5). The columns are means \pm standard deviations, and the same letters above the columns indicate insignificant differences $(P>0.05)$. LA, lactic acid; $A O$, aqueous ozone. 
Effects of sequential washing on lettuce electrolyte leakage, weight loss, and polyphenolic content

The extent of damage to lettuce samples after washing with various treatments was estimated based on electrolyte leakage. As shown in Fig. 2a, all disinfection treatments caused significant electrolyte leakage compared with tap water. After washing with $2 \mathrm{mg} \mathrm{L}^{-1}$ AO for $120 \mathrm{~s}$, the electrolyte leakage was $1.26 \%$, which was significantly lower than the values of the other disinfection treatments. Compared with LA (120 s), the combination treatment with LA (90 s) plus AO (30 s) did not lead to additional electrolyte leakage. These results indicated that AO had no effect on electrolyte leakage, which was mainly caused by LA.

Similarly, another study demonstrated that electrolyte leakage rates from lettuce were $1.43 \%$ and $1.41 \%$ following treatment with $1 \%$ hydrogen peroxide and $1 \%$ hydrogen peroxide plus electrolyzed water, respectively, which were lower than the rate $(3.11 \%)$ of samples treated with $1 \%$ hydrogen peroxide plus $0.6 \% \mathrm{CA}^{32}$ In contrast, electrolyte leakage in fresh-cut cilantro was found to be comparable between samples washed with $\mathrm{AO}$ for $5 \mathrm{~min}$ and the control (14.13 vs. 15.78 $\left.\mu \mathrm{s} \mathrm{cm}^{-1}\right) .{ }^{39}$ Moreover, our results showed that the electrolyte leakage of samples treated with LA plus AO was similar to that of chlorine.

During subsequent storage for up to 5 days, nonsignificant weight loss was observed in the disinfection groups (Fig. 2b). Similarly, the polyphenolic content of the disinfection treatment groups ranged from 282.84 to $298.91 \mathrm{mg} \mathrm{kg}^{-1} \mathrm{GAE}$, which was similar to that in the tap water group $\left(289.24 \mathrm{mg} \mathrm{kg}^{-1} \mathrm{GAE}\right.$, Fig. 2c). These results were inconsistent with our initial speculation because the different electrolytes could lead to differences in quality loss. ${ }^{32,40}$ This phenomenon may result from the slight damage caused by sanitizers and was not sufficient to cause visual quality loss, such as browning. During subsequent storage, the cell self-repair prevented additional losses in weight and polyphenolic contents. ${ }^{\mathbf{4 0 , 4 1}}$

\section{Reduction in microbial counts}

The results showed that the microbial counts of $E$. coli $\mathrm{O} 157: \mathrm{H} 7$ in the control group were $6.54 \pm 0.20 \log \mathrm{CFU} \mathrm{g}^{-1}$ on day 0, 7.05 $\pm 0.26 \log \mathrm{CFU} \mathrm{g}^{-1}$ on day 3 , and $7.41 \pm 0.19 \log \mathrm{CFU} \mathrm{g}^{-1}$ on day 5. AMCs were $5.77 \pm 0.27 \log \mathrm{CFU} \mathrm{g}^{-1}$ on day $0,6.48 \pm 0.27 \mathrm{log}$ CFU g ${ }^{-1}$ on day 3 , and $7.13 \pm 0.30 \log$ CFU g ${ }^{-1}$ on day 5 . APCs

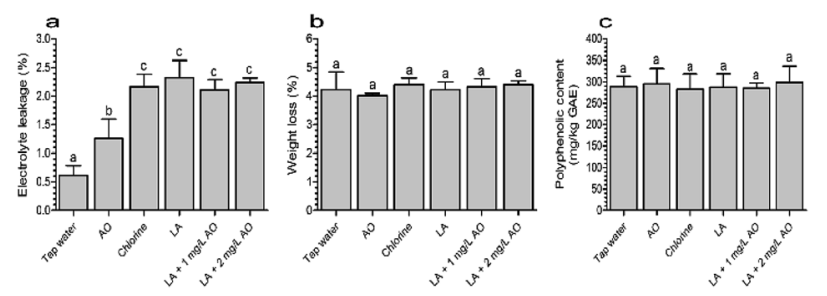

Fig. 2 Effects of various treatments on electrolyte leakage on day 0 (a), weight loss on day 5 (b), and polyphenolic content on day 5 (c). The columns indicate means \pm standard deviations, and the same letters above the columns indicate insignificant differences $(P>0.05)$. $\mathrm{GAE}$, gallic acid equivalent; $\mathrm{LA}$, lactic acid; $\mathrm{AO}$, aqueous ozone. were $5.73 \pm 0.20 \log \mathrm{CFU} \mathrm{g}^{-1}$ on day $0,6.44 \pm 0.24 \log \mathrm{CFU} \mathrm{g}^{-1}$ on day 3 , and $7.13 \pm 0.32 \log \mathrm{CFU} \mathrm{g}^{-1}$ on day 5 . M\&Y were $4.86 \pm$ $0.17 \log \mathrm{CFU} \mathrm{g}^{-1}$ on day $0,5.81 \pm 0.15 \log \mathrm{CFU} \mathrm{g}^{-1}$ on day 3 , and $6.57 \pm 0.14 \log \mathrm{CFU} \mathrm{g}^{-1}$ on day 5 . After disinfection with various treatments, the counts of $E$. coli $\mathrm{O} 157: \mathrm{H} 7$ were all significantly reduced compared with those of tap water (Fig. 3a). Among these treatments, independent AO disinfection led to the lowest E. coli O157:H7 counts, with a $0.8 \log$ reduction, which was significantly lower than that of the other treatments. These results were similar to those of the study by Neal et al. ${ }^{15}$ The authors found that LA treatment caused 2.7 and $2.3 \log$ reductions in E. coli O157:H7 and Salmonella counts, respectively, whereas AO only reduced the counts by 0.6-1.1 and 0.9-1.0 log, respectively. The $E$. coli $\mathrm{O} 157: \mathrm{H} 7$ reduction by LA was consistent with that of chlorine, similar to the results described by Akbas and Olmez. ${ }^{21}$

The largest reduction was caused by $90 \mathrm{~s}$ LA plus $30 \mathrm{~s}$ AO, with a $\log$ reduction of $1.65-1.69$, which was not significantly higher than that of the independent $120 \mathrm{~s}$ LA disinfection plus $30 \mathrm{~s}$ tap water, inconsistent with the observations described in Table 1. However, the trends (Fig. 3) were similar to those shown in Table 1. According to previous reports, after washing with organic acid sanitizer, LA and AA are more effective than chlorine in reducing AMCs and E. coli O157:H7 counts on freshcut lettuce and result in effective control of microbial growth during storage. ${ }^{38}$ In contrast, Samara and Koutsoumanis ${ }^{19}$ found that acid disinfection stimulates the growth of L. monocytogenes during storage. In this work, we found that E. coli O157:H7 reduction by LA plus AO was significantly greater than that of LA, chlorine, and AO disinfection alone during storage (Fig. 3a).

For naturally present microbes, we found that AO plus LA led to the largest AMC reduction after washing, which was
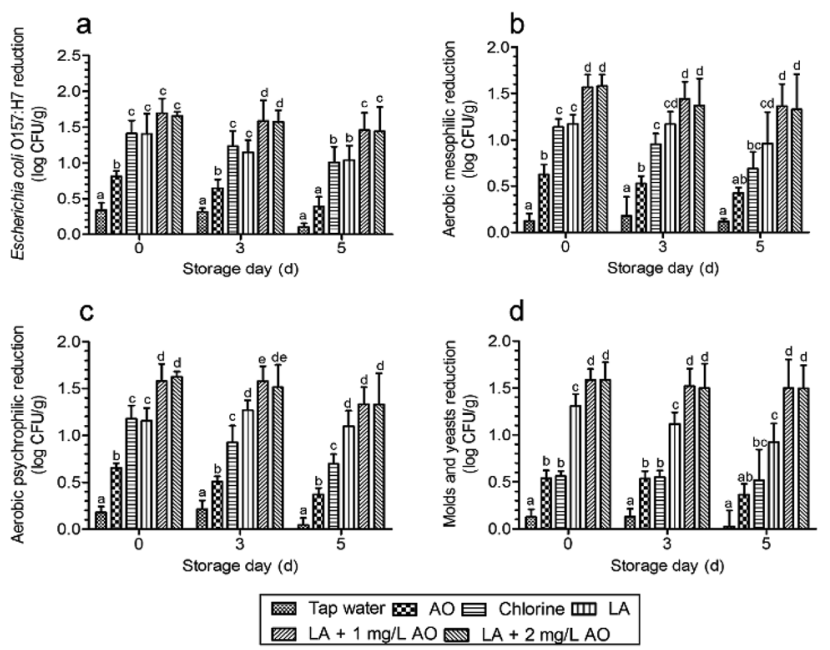

Fig. 3 Effects of various treatments on Escherichia coli O157:H7 (a) and naturally present microbes $(b-d)$ during storage $\left(0-5\right.$ days at $5^{\circ} \mathrm{C}$ ). The columns show means \pm standard deviations, and the different letters above the columns indicate significant differences $(P<0.05)$ among the presented timepoint groups. Microbial reduction indicates the difference in microbial counts between the control and treatment groups at the same time point. LA, lactic acid; AO, aqueous ozone. 
significantly larger than that of the other treatments (Fig. 3b). During subsequent storage, LA plus AO also led to the largest AMC reduction, which was significantly larger than those of AO and chlorine alone. APC reductions after washing and during storage were similar to AMC reduction (Fig. 3c). For M\&Y, the count reduction induced by chlorine was significantly smaller than that induced by LA (Fig. 3d), consistent with the results described by Allende et al. ${ }^{33}$ Compared with other disinfection treatments, LA plus AO significantly reduced M\&Y counts after disinfection and during storage.

Overall, the largest microbial reduction was achieved after LA plus AO treatment (Fig. 3a-d), which may result from the different disinfection mechanisms of LA and AO. As an oxidizing agent, ozone kills bacteria by reacting with components of the cell envelope, spore coat, or viral capsid. ${ }^{42}$ The antibacterial activity of organic acids is traditionally attributed to cellular anion accumulation, which is determined by the proportion of undissociated molecules. ${ }^{43}$ Compared with dissociated anions, undissociated acidic molecules have greater lipophilicity, allowing them to more easily penetrate the microbial cell membrane. ${ }^{43}$ After penetration, the higher intracellular $\mathrm{pH}$ promotes the dissociation of acidic molecules, and the anions accumulate in the cell and exert toxic effects on the cell membrane, acid-sensitive proteins, DNA, and RNA. ${ }^{\mathbf{2 0 , 4 3}}$ Thus, protein denaturation, DNA replication suppression, and membrane disruption are common antibacterial mechanisms. ${ }^{\mathbf{2 0 , 4 3}}$ In this study, we speculate that the mechanism of action of the sequential disinfection (LA plus AO) was as follows: lactate anions act on DNA, proteins, and membranes after penetrating bacterial cells, and after AO washing, the cell membrane is oxidized to accelerate membrane disruption. In contrast, sequential washing with the combined use of sanitizers of the same type (i.e., one with a similar antimicrobial mechanism of action) will not significantly reduce microbial counts compared with samples subjected to independent treatments. For example, application of acidic electrolyzed water alone or followed by washing with AO reduces AMC on cilantro by 0.66 and $0.62 \mathrm{log}$, respectively, ${ }^{44}$ and AMCs after treatment with both ozone and chlorine show a similar log reduction to that of samples treated with chlorine only. ${ }^{45}$

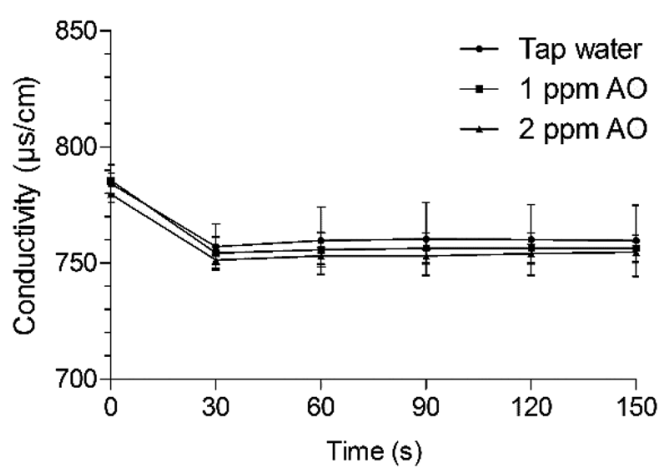

Fig. 4 Changes in conductivity after immersing the sample washed with $1 \%$ LA for $90 \mathrm{~s}$. Values are expressed as means \pm standard deviations. $\mathrm{AO}$, aqueous ozone.
Interestingly, we found that the microbial counts were not additively reduced by increasing the AO concentration from 1 to $2 \mathrm{mg} \mathrm{L}^{-1}$ (Fig. 3a-d and Table 1). For AO, additional microbial reductions were achieved by dramatically increasing the concentration, such as from 3 to $10 \mathrm{ppm}$, causing a significant decrease in the AMC. ${ }^{46}$ Moreover, $4 \mathrm{mg} \mathrm{L}^{-1} \mathrm{AO}$ yielded a $1.7 \mathrm{log}$ reduction in the $\mathrm{AMC},{ }^{47}$ which is comparable to the decrease observed with $2 \mathrm{mg} \mathrm{L}^{-1} \mathrm{AO}(1.5 \mathrm{log}) .{ }^{48}$ Different results were also obtained for pathogen disinfection. For example, L. monocytogenes counts were reduced by $5 \log$ after a $5 \mathrm{~min}$ exposure to 5 ppm AO, ${ }^{49}$ although other investigators reported a reduction of only $0.94 \mathrm{log}$ under the same conditions. ${ }^{26}$ For practical applications, it is important to maintain ozone concentrations as low as possible to protect the health of workers and reduce corrosion. $^{36,50}$ In addition, when preparing large-scale AO for a processing line, it is difficult to obtain concentrations exceeding $3 \mathrm{mg} \mathrm{L}^{-1}$.

\section{Acid removal ability of $\mathrm{AO}$ and water quality improvement potential of $\mathrm{LA}$ residue}

Conductivity is an indicator of the concentration of minerals and ionic compounds dissolved in solution. We investigated whether AO can be used instead to remove residual acid. After immersion in LA for $90 \mathrm{~s}$, lettuce samples were washed with tap water or 1 or $2 \mathrm{ppm} \mathrm{AO,} \mathrm{which} \mathrm{yielded} \mathrm{conductivity} \mathrm{values} \mathrm{of}$ 784.33, 785.67, and $779.67 \mu \mathrm{s} \mathrm{cm}^{-1}$, respectively (Fig. 4). Organic acids react with minerals and elements dissolved in water because of their acidity and complexing ability. ${ }^{51}$ The conductivity of drinking water is $50-1500 \mu \mathrm{s} \mathrm{cm}^{-1}$ and should be maintained as low as possible in water used to wash fresh produce. After immersion in tap water and 1 and $2 \mathrm{mg} \mathrm{L}^{-1} \mathrm{AO}$ for $30 \mathrm{~s}$, the conductivity decreased by 27.33, 28, and 28.33 $\mu \mathrm{s} \mathrm{cm}{ }^{-1}$, respectively. Thus, tap water and 1 and $2 \mathrm{mg} \mathrm{L}^{-1} \mathrm{AO}$ did not differ in acid-removal ability, and the acid residue was easily removed within $30 \mathrm{~s}$.

Moreover, crosscontamination during washing is a major concern for researchers in the field of minimal processing. The technology using ozone to improve water quality has advanced. Thus, the preparation of AO in this proposed hurdle technology was important not only for sequential disinfection but also to improve the water quality during AO preparation, consequently reducing crosscontamination risks and water consumption. However, the AO concentration was greatly affected by water chemical oxygen demand (COD), which increased as the washing time was prolonged. Thus, in a subsequent work, we will determine the relationships between fresh wash water COD and $\mathrm{AO}$ concentrations and design a corresponding appropriate processing line.

\section{Conclusions}

Hurdle technology is attracting increasing interest because it can provide additional microbial reductions compared with traditional independent disinfection strategies. In this study, we designed a hurdle technology using LA disinfection followed by AO disinfection (LA plus AO) and compared its disinfection 
efficacy and resulting lettuce quality with those of traditional disinfection strategies (LA or chlorine disinfection plus tap water washing and independent $\mathrm{AO}$ disinfection). The results indicated that this hurdle technology led to the largest reductions in AMCs, APCs, M\&Y, and E. coli $\mathrm{O} 157: \mathrm{H} 7$ counts during storage. Moreover, conductivity analysis showed that the acid removal ability of this hurdle technology was consistent with those of the other disinfection methods. Quality analysis indicated that LA plus AO disinfection did not increase phenolic contents or colour loss compared with other traditional disinfection methods. Interestingly, we also found that the disinfection efficacy of chlorine was similar to that of LA when disinfecting bacteria, whereas the disinfection of fungi by chlorine was significantly less efficient than by LA. Taken together, these results provide a reference for the application of LA plus AO disinfection to control microbial contamination on fresh produce.

\section{Conflicts of interest}

There are no conflicts to declare.

\section{References}

1 P. Putnik, D. B. Kovačević, K. Herceg, S. Roohinejad, R. Greiner, E. D. A. Bekhit and B. Levaj, Food Control, 2017, 81, 55-64.

2 A. N. Olaimat and R. A. Holley, Food Microbiol., 2012, 32, 119.

3 E. Scallan, R. M. Hoekstra, F. J. Angulo, R. V. Tauxe, M.-A. Widdowson, S. L. Roy, J. L. Jones and P. M. Griffin, Emerging Infect. Dis., 2011, 17, 7.

4 R. M. Callejón, M. I. Rodríguez-Naranjo, C. Ubeda, R. Hornedo-Ortega, M. C. Garcia-Parrilla and A. M. Troncoso, Foodborne Pathog. Dis., 2015, 12, 32-38.

5 M. A. De Oliveira, V. M. De Souza, A. M. M. Bergamini and E. C. P. De Martinis, Food Control, 2011, 22, 1400-1403.

6 J. N. Ssemanda, M. W. Reij, G. van Middendorp, E. Bouw, R. van der Plaats, E. Franz, C. M. Muvunyi, M. C. Bagabe, M. H. Zwietering and H. Joosten, Food Control, 2018, 89, 86-96.

7 L. Ma, M. Zhang, B. Bhandari and Z. Gao, Trends Food Sci. Technol., 2017, 64, 23-38.

8 D. Gombas, Y. Luo, J. Brennan, G. Shergill, R. Petran, R. Walsh, H. Hau, K. Khurana, B. Zomorodi, J. Rosen, R. Varley and K. Deng, J. Food Prot., 2017, 80, 312-330.

9 A. Meireles, E. Giaouris and M. Simões, Food Res. Int., 2016, 82, 71-85.

10 H. Ölmez and U. Kretzschmar, LWT-Food Sci. Technol., 2009, 42, 686-693.

11 C. Goodburn and C. A. Wallace, Food Control, 2013, 32, 418427.

12 U. De Corato, Crit. Rev. Food Sci. Nutr., 2019, 1-36.

13 R. J. Bull, D. A. Reckhow, X. Li, A. R. Humpage, C. Joll and S. E. Hrudey, Toxicology, 2011, 286, 1-19.

14 L. Chen, H. Zhang, Q. Liu, X. Pang, X. Zhao and H. Yang, Int. J. Food Microbiol., 2019, 295, 41-48.
15 J. A. Neal, M. Marquez-Gonzalez, E. Cabrera-Diaz, L. M. Lucia, C. A. O'Bryan, P. G. Crandall, S. C. Ricke and A. Castillo, Food Res. Int., 2012, 45, 1123-1128.

16 A. Martínez-Sánchez, A. Allende, R. N. Bennett, F. Ferreres and M. I. Gil, Postharvest Biol. Technol., 2006, 42, 86-97.

17 G. Finten, M. V. Agüero and R. J. Jagus, LWT-Food Sci. Technol., 2017, 82, 318-325.

18 Y. Huang and H. Chen, Food Control, 2011, 22, 1178-1183.

19 A. Samara and K. P. Koutsoumanis, Int. J. Food Microbiol., 2009, 129, 1-7.

20 J. Wang, D. Tao, S. Wang, C. Li, Y. Li, F. Zheng and Z. Wu, RSC Adv., 2019, 9, 17514-17520.

21 M. Y. Akbas and H. Ölmez, Lett. Appl. Microbiol., 2007, 44, 619-624.

22 S. Van Haute, M. Uyttendaele and I. Sampers, Int. J. Food Microbiol., 2013, 167, 161-169.

23 M. I. Gil, M. V. Selma, F. Lopez-Galvez and A. Allende, Int. J. Food Microbiol., 2009, 134, 37-45.

24 S. Van Haute, I. Tryland, C. Escudero, M. Vanneste and I. Sampers, LWT-Food Sci. Technol., 2017, 75, 301-304.

25 S. Van Haute, I. Tryland, A. Veys and I. Sampers, Food Control, 2015, 50, 173-183.

26 H. G. Yuk, M. Y. Yoo, J. W. Yoon, K. D. Moon, D. L. Marshall and D. H. Oh, J. Food Sci., 2006, 71, 83-87.

27 H.-G. Yuk, M.-Y. Yoo, J.-W. Yoon, D. L. Marshall and D.-H. Oh, Food Control, 2007, 18, 548-553.

28 B. Dhillon, D. Wiesenborn, C. Wolf-Hall and F. Manthey, J. Food Sci., 2009, 74, E396-E403.

29 R. Singla, A. Ganguli and M. Ghosh, Food Control, 2011, 22, 1032-1039.

30 C. Wang, T. Chang, H. Yang and M. Cui, Food Control, 2015, 47, 231-236.

31 H. Bader, Ozone: Sci. Eng., 2008, 4, 169-176.

32 J. Zhang and H. Yang, Food Control, 2017, 72, 20-26.

33 A. Allende, M. V. Selma, F. López-Gálvez, R. Villaescusa and M. I. Gil, Postharvest Biol. Technol., 2008, 49, 155-163.

34 V. M. Gómez-López, A. Marín, M. S. Medina-Martínez, M. I. Gil and A. Allende, Postharvest Biol. Technol., 2013, 85, 210-217.

35 V. L. Singleton, R. Orthofer and R. M. Lamuela-Raventós, Methods Enzymol., 1999, 299, 152-178.

36 M. Glowacz and D. Rees, J. Sci. Food Agric., 2016, 96, 46374643.

37 D. Bermúdez-Aguirre and G. V. Barbosa-Cánovas, Food Control, 2013, 29, 82-90.

38 S. V. Poimenidou, V. C. Bikouli, C. Gardeli, C. Mitsi, P. A. Tarantilis, G. J. Nychas and P. N. Skandamis, Int. J. Food Microbiol., 2016, 220, 6-18.

39 H. Wang, H. Feng and Y. Luo, Food Res. Int., 2004, 37, 949956.

40 S. P. Salgado, A. J. Pearlstein, Y. Luo and H. Feng, LWT-Food Sci. Technol., 2014, 56, 261-268.

41 X. Fan, K. J. Sokorai, B. A. Niemira, R. S. Mills and M. Y. Zhen, HortScience, 2012, 47, 1108-1112.

42 A. Alexopoulos, S. Plessas, S. Ceciu, V. Lazar, I. Mantzourani, C. Voidarou, E. Stavropoulou and E. Bezirtzoglou, Food Control, 2013, 30, 491-496. 
43 A. Lianou, K. P. Koutsoumanis and J. N. Sofos, in Microbial Decontamination in the Food Industry, Woodhead Publishing Inc., Oxford, 2012, pp. 592-664.

44 N. Singh, R. K. Singh, A. K. Bhunia and R. L. Stroshine, LWTFood Sci. Technol., 2002, 35, 720-729.

45 A. Garcia, J. R. Mount and P. M. Davidson, J. Food Sci., 2003, 68, 2747-2751.

46 S. Koseki and S. Isobe, J. Food Prot., 2006, 69, 154-160.
47 M. Y. Akbas and H. Ölmez, J. Sci. Food Agric., 2007, 87, 26092616.

48 H. Ölmez and M. Y. Akbas, J. Food Eng., 2009, 90, 487-494.

49 S. L. Rodgers, J. N. Cash, M. Siddiq and E. T. Ryser, J. Food Prot., 2004, 67, 721-731.

50 N. Tzortzakis and A. Chrysargyris, Food Rev. Int., 2016, 33, 270-315.

51 S. Karlsson, H. Wolrath and J. Dahlén, Water Res., 1999, 33, 2569-2578. 